\title{
0 problema do argumento do quarto chinês para a superinteligência de Bostrom
}

\author{
The chinese room argument and Bostrom's superintelligence
}

\begin{abstract}
Gustavo Coelho de Oliveira ${ }^{1}$
1 Universidade do Sul de Santa Catarina

E-mail: olyverha@gmail.com Orcid: http://orcid.org/0000-0001-8128-9958 Lattes: http://lattes.cnpq.br/6105247380421681
\end{abstract}

RESUMO: Um dos problemas a serem superados pelos defensores de uma IA Forte é o argumento do quarto chinês de J. Searle. Este artigo propôs-se a analisar se o argumento estruturado no experimento de pensamento do quarto chinês foi refutado pelo modelo de superinteligência. Analisamos o modelo de N. Bostrom e verificamos que ele não é suficiente para rejeitar qualquer premissa do argumento de Searle. Mesmo ampliando a discussão com a argumentação de S. Bringsjord, sobre a necessidade ou não de consciência para uma máquina maliciosa, demonstramos não ser possível sustentar a aceitabilidade racional do modelo de superinteligência.

Palavras-chave: Superinteligência; Quarto Chinês; Inteligência Artificial.

ABSTRACT: One of the problems to be overcome by the supporters of a Strong Al is the argument of J. Searle's chinese room. This paper sets out to analyze whether the argument structured in the chinese room experiment was refuted by the superintelligence model. We analyze N. Bostrom's model and find that it is not strong enough to reject any premise of Searle's argument. Even considering the argument of S. Bringsjord, on the necessity or not of conscience for a malicious machine, we demonstrate that it is not possible to sustain the rational acceptability of the superintelligence model.

Keywords: Superintelligence; Chinese Room; Artificial Intelligence.

\section{Introdução}

Alan M. Turing, matemático britânico, em 1950 publica seu conhecido artigo, Computing Machinery and Intelligence, considerando a questão "máquinas podem pensar?" e propondo, como uma melhor forma de abordar essa questão, um jogo que ele intitula como “o jogo da imitação”, esse que passaria a ser conhecido como o Teste de Turing. Juntamente à abordagem da Inteligência Artificial (IA), o referido artigo procurava argumentar a favor da capacidade de máquinas reproduzirem um comportamento inteligente semelhante ao humano, concluindo, inclusive, a possibilidade de máquinas pensantes em um horizonte pouco distante.

Nos anos que se seguiram, a questão da inferência de que máquinas com inteligência geral comparada à dos homens poderiam simplesmente emergir a partir da execução dos algoritmos corretos, estimulou abundantes debates no campo da filosofia da mente. Entre os filósofos que se destacam, com contribuição significativa para o avanço das discussões, certamente figura o americano John Searle, célebre pelo seu experimento mental denominado "O Quarto Chinês", descrito no seu artigo Minds, brains and programs (SEARLE, 1980). O ponto central do experimento é demonstrar que a manipulação formal de símbolos, ou, uma sintaxe, não é condição suficiente para a semântica.

No esteio da ideia do surgimento de uma singularidade tecnológica, nos moldes popularizados por 
Vinge (1993) e Kurzweil (2005), o filósofo sueco Nick Bostrom, procurou desenvolver a perspectiva de uma superinteligência de máquina, definida nos termos de "qualquer intelecto que exceda em muito o desempenho cognitivo dos seres humanos em, virtualmente, todos os domínios de interesse." (BOSTROM, 2018, p. 55). Nesse sentido, a ideia relacionada à singularidade que interessa à Bostrom é a eventualidade de um irromper de inteligência de máquina. Relativo a isso, há a preocupação em se considerar a possibilidade de que os esforços recentes, em direção a uma inteligência artificial geral, envolvam riscos existenciais, sendo sustentada a viabilidade do cenário em que uma IA superinteligente seria plenamente capaz para delinear o futuro de acordo com suas próprias motivações.

Isto posto, o tema do presente trabalho traduz-se na tentativa de responder à seguinte questão: o argumento do quarto chinês é superado pela superinteligência de Bostrom? Assim, partindo-se do projeto de superinteligência proposto por Bostrom (2018), este artigo tenciona demonstrar se o argumento estruturado no experimento de pensamento do quarto chinês, idealizado por Searle (1980), foi superado ou não. A pesquisa justifica-se no fato de propor um debate sobre as fronteiras do pensamento, da intencionalidade e do futuro da máquina inteligente, ampliando, assim, a perspectiva sobre o problema mente-cérebro, além de propor preceitos epistemológico e metodológicos para a investigação dessa relação.

\section{O Argumento do Quarto Chinês}

Ao formular seu argumento, do qual o experimento mental do quarto chinês é elemento constituinte, Searle (1990, p. 27) intentava explicitar os pressupostos daquilo que ele caracteriza como IA Forte. Nesse sentido, IA Forte é a tese de que, para a cognição ou estados mentais em mentes digitais, bastaria a implementação dos algoritmos corretos ou, em outras palavras, para se estabelecer o pensamento, seria necessário apenas o programa apropriado, por si mesmo, rodando em um hardware adequado. Por outro lado, IA Fraca é a concepção de que os modelos computacionais podem contribuir na compreensão do intelecto humano através da simulação, e não da efetivação propriamente dita da mente.

Relativo a isso, os defensores da IA Forte acreditam que o teste de Turing é o método válido para inferir se máquinas possuem ou não estados mentais. O teste é definido segundo a seguinte disposição: caso um computador apresente um desempenho cognitivo geral indistinguível do desempenho de um ser humano, devemos considerar que ele obteve sucesso no teste. Assim, o programa implementado em tal máquina não seria simplesmente um modelo de intelecto humano, mas uma mente no mesmo sentido que uma mente humana o é. Há, portanto, o entendimento, segundo a tese da IA Forte, de que ao rodar o programa, com inputs e outputs corretos, literalmente estaríamos criando mentes. (SEARLE, 1990).

Para contestar esta tese, Searle descreve a experiência de pensamento do quarto chinês nos termos que se seguem. Consideremos uma linguagem ininteligível para nós. No caso de Searle, o chinês. Suponhamos que estamos em um quarto com recipientes cheios de símbolos chineses. Admitamos também que dentro do quarto há um livro de regras (o programa) que faz a correspondência de símbolos chineses com outros símbolos chineses apenas pelo formato, não requerendo que nós os entendamos. Imaginemos que pessoas fora da sala, com fluência no chinês, introduzam por uma abertura no quarto pedaços de papeis que contém símbolos (inputs), e em resposta, após a manipulação do livro de regras, nós devolvamos outro papel com porções de símbolos (outputs). Deste modo, suponhamos que o livro de regras garanta que nossas respostas sejam indistinguíveis das respostas que poderiam ser dadas por um falante nativo de chinês.

Diante do contexto descrito, somos obrigados a aceitar que nós, dentro da sala, passamos no teste de Turing, mesmo não compreendendo uma única palavra em chinês. Assim como um computador, 
manipulamos formalmente símbolos, porém sem lhes atribuir nenhum significado. Portanto, infere-se que apenas a manipulação de símbolos não é capaz de assegurar o entendimento, a cognição ou qualquer estado mental. Sendo assim, esclarece Searle (2007), se mesmo o homem, dentro da sala, possuindo toda a sintaxe que programadores de computador podem fornecer ainda não compreende o significado das palavras, então, de igual modo, nenhum outro computador digital poderá compreender, pois nenhuma máquina digital, sendo um mecanismo de manipulação de símbolos, possui algo que esse homem não tem.

Destarte, procurando refutar decisivamente a ideia de que a implementação do programa correto seria suficiente para a intencionalidade, Searle (1997, p. 11-12) formula seu argumento composto por três premissas e uma conclusão:

P1) Programas são totalmente sintáticos;

P2) Mentes têm semântica;

P3) Sintaxe não é a mesma coisa que a semântica, nem é, por si só, suficiente para garantir um conteúdo semântico;

C1) Portanto, programas não são mentes. Q.E.D. ${ }^{1}$

\section{A Superinteligência de Bostrom}

Máquinas com inteligência geral comparável à dos humanos, possuindo bom senso, aprendizado, raciocínio e capazes de processar informações de domínios naturais e abstratos são esperadas desde meados da década de 1940. (BOSTROM, 2018, p. 25). Apesar dos inegáveis avanços permitidos pelo uso de máquinas digitais em nossa era e a perspectiva de uma primavera tecnológica inexorável (KURZWEIL, 2007), há aqueles que argumentam a favor de uma prudência frente à expectativa de uma revolução da inteligência artificial. Isto porque, justificam, a IA de nível humano não é a última parada nesse avançar, e sim, a IA sobre-humana, ou, superinteligência.

Alusivo a isso, Nick Bostrom desponta como um dos principais defensores de contramedidas e controle sobre uma possível explosão da inteligência digital. Para tanto, Bostrom (2018, p. 56) procura delimitar e caracterizar a ideia de superinteligência, nos seguintes termos: "sistemas que tenham um nível sobrehumano de inteligência geral". Ademais, o conceito é expandido através de três formas diferentes de superinteligência, as quais na prática, argumenta o filósofo, são equivalentes. São, a priori, grupos de supercapacidades, apresentadas da seguinte forma: superinteligência rápida, superinteligência coletiva e superinteligência de qualidade.

A superinteligência rápida é caracterizada como "um sistema que pode fazer tudo o que um intelecto humano é capaz de fazer, porém muito mais rapidamente”. (BOSTROM, 2018, p. 108). Tal modelo é comparado a uma emulação completa do cérebro, porém, executada em um hardware com aceleração na ordem de milhares de vezes. Para essa mente, explica Bostrom, haveria uma expansão aparente do tempo e os objetos digitais seriam os artefatos ideais para manipulação, sendo que as fronteiras para esses agentes com grande aceleração se restringiriam aos limites das próprias leis da física.

Por outro lado, a superinteligência coletiva, argumenta Bostrom (2018, p. 111), seria um "sistema composto de um grande número de intelectos menores, de forma que o seu desempenho total supere significativamente, em diversas áreas gerais do conhecimento, qualquer sistema cognitivo atual". Cabe, porém, uma ressalva quanto ao sentido de coletivo. Um intelecto digital coletivo não seria meramente uma

${ }^{1}$ Quod erat demonstrandum. 
paralelização em baixo nível de hardware, mas é ilustrado melhor como uma potencialização, a nível de inteligência, de agentes autônomos de uma comunidade atuando de maneira colaborativa. Tal sistema seria aperfeiçoado através do incremento da quantidade ou da qualidade dos agentes, ou mesmo da ampliação de sua organização. Por fim, a superinteligência coletiva caminharia para se converter em um intelecto unificado, e após um crescimento suficiente em integração, transformar-se-ia em uma superinteligência de qualidade.

Uma superinteligência de qualidade seria distinguida nos termos de "um sistema que é no mínimo tão rápida quanto uma mente humana e qualitativamente muito mais inteligente". (BOSTROM, 2018, p. 115). À vista desse conceito, a qualidade de uma superinteligência seria superior à inteligência humana, no mesmo modo e sentido que a inteligência humana é superior à das alimárias conhecidas. Assim, a distinção de predicado residiria na ideia de talentos cognitivos possíveis, que nenhum outro humano possui, mas que em sistemas inteligentes, com poder computacional comparável ao cérebro humano, seriam plenamente factíveis.

Por fim, Bostrom (2018, p. 107) procura demonstrar a vantagem da inteligência digital, como substrato de máquina, frente ao substrato biológico. Tanto pelos recursos computacionais, quanto por sua arquitetura, a inteligência de máquina manifestaria vantagens relativas ao hardware: velocidade e número dos elementos computacionais, velocidade interna de comunicação, capacidade de armazenamento, confiabilidade e duração dos sensores; bem como benefícios proporcionados especificamente pela natureza de software: editabilidade, duplicabilidade, coordenação de objetivos, compartilhamento de memória e modularidade de algoritmos. Tais conveniências, argumenta Bostrom, propiciadas pela condição de hardware e software combinado nas mentes digitais, possibilitaria uma superioridade incrível, as quais os humanos não possuiriam condições para se contrapor.

\section{O problema do Quarto Chinês para a Superinteligência}

A tese central de Bostrom é que deveríamos nos concentrar profusamente na possibilidade real de uma explosão de inteligência que poderá vir a ser maligna, incorrendo em uma catástrofe existencial para a humanidade (BOSTROM, 2018, p. 226). Para tanto, uma superinteligência computacional motivada a nos destruir, baseada em suas próprias crenças e desejos (conteúdo semântico), precisa possuir intenção e motivação real, e não meramente um comportamento malicioso simulado por uma IA, programada por uma mente humana consciente, projetada para se comportar como se possuísse uma realidade psicológica. Computadores digitais são máquinas sintáticas. Mentes, por outro lado, teriam conteúdo semântico. Assim, a ideia de uma singularidade tecnológica perversa só não seria mais um alarmismo equivocado, caso o modelo de mente digital, contrariamente ao argumento chinês, produzisse, a partir da sintaxe, semântica.

Comecemos examinando P1: seria possível negar que programas são somente sintáticos? Programas são conjuntos de regras, simbolicamente estabelecidas, que permitem que um computador digital, através da manipulação desses símbolos, processe informação. Nesse sentido são definidos de maneira puramente formal, não sendo intrínsecos à física ou à natureza. De outro modo, os zeros e uns, ou quaisquer outras figuras simbólicas que constituam um determinado programa, não possuem propriedades físicas essenciais e causais, podem ser implementados em qualquer meio físico e contém um significado atribuído por um observador. Dessarte, "programas e símbolos são noções puramente abstratas...sendo manipulados com referência a qualquer significado". (SEARLE, 1990, p. 27). Portanto programas consistem inteiramente em regras referentes a entidades sintáticas, isto é, regras para manipulação de símbolos. Negar P1 é rejeitar parte do significado daquilo que definimos como programa de computador. 
Com relação à P2, se formos contra a segunda premissa, precisamos negar que estados mentais possuem conteúdo semântico intrínseco. Entretanto, mesmo que meus pensamentos ocorram em conjuntos de símbolos, há algo a mais nesse fenômeno mental do que apenas signos abstratos, um elemento de subjetividade ontológica, pois esses símbolos por si mesmos não têm significado. Se meus pensamentos são acerca de algo, então as séries de "símbolos devem ter um significado, que faz que os pensamentos sejam acerca dessas coisas”. (SEARLE, 1984, p. 42). Em outros termos, precisaríamos negar os próprios estados mentais, afirmando a não existência de experiências subjetivas, internas e privadas, o que obviamente, contradiz a intuição comum.

Assim, o caminho mais promissor para refutação do argumento parece ser demonstrar que P3 é falsa. Frente às outras duas premissas, essa seria a via mais eficiente, pois, obtendo-se o sucesso, as projeções e preocupações de Bostrom adquirem uma plausibilidade dissuasória.

Não obstante, a ilustração do quarto chinês procura justamente demonstrar o princípio geral de P3: a mera manipulação formal de símbolos não é por si só suficiente para garantir a presença de semântica. Apenas processar símbolos não garante o conhecimento do que eles se significam. Assim, o que há aqui é "uma distinção entre elementos sintáticos, os quais não possuem nenhum significado ou conteúdo intrínseco, e aqueles fenômenos que têm conteúdo intrínseco”. (SEARLE, 1990, p. 27).

Esse é o ponto desenvolvido por Searle (2014) em What your computer can't know, onde o filósofo faz uma crítica direta à perspectiva de uma superinteligência maliciosa conforme argumentada por Bostrom. Ao considerar o cerne da ideia, Searle procura inicialmente estabelecer a distinção entre objetividade e subjetividade. Para isso, diferencia a ideia de um sentido que é epistêmico, onde epistêmico significa ter a ver com conhecimento, e um sentido, que é ontológico, onde ontológico está relacionado à existência. Assim, se digo que Descartes nasceu em 31 de março de 1596, esta afirmação é epistemicamente objetiva, pois a verdade dessa proposição não depende de nenhuma atitude ou sentimento de quem a expressa. Em contrapartida, se afirmo que, na minha opinião, Descartes foi o maior filósofo que já viveu, essa asserção será epistemicamente subjetiva, pois depende da minha expectativa pessoal para com ele. Tão importante quanto essa distinção epistemológica, é o discernimento ontológico entre os modos de existência. Muitas coisas existem independentes de serem experienciadas, como moléculas, pedras e árvores. Elas são ontologicamente objetivas. Todavia, algumas entidades só existem na medida em que são experenciadas, como a dor, a alegria e o medo, que são ontologicamente subjetivas.

Outra distinção, que é essencial para compreender noções como computação e inteligência, é sobre objetos da realidade. Searle procura ressaltar a diferença entre dois tipos de objetos: aqueles que são observer independent (OI), caracterizados por possuir uma existência independente das nossas atitudes ou pensamentos sobre eles; e aqueles que só existem em relação a observadores, pois dependem de certas atitudes que indivíduos têm com relação a eles, e por isso são observer dependent ou observer relative (OR). Átomos, montanhas e planetas pertencem ao primeiro tipo. Dinheiro, governo e casamento, contudo, são todos OR. De fato, o que faz um pedaço de papel em nossa carteira ser dinheiro não é nenhuma característica intrínseca da sua química ou física, mas sim as atitudes que temos em relação a ele. Assim, todos os fenômenos relativos ao observador são criados pela consciência humana, possuindo, portanto, um elemento de subjetividade ontológica.

Para Searle (2014) tais distinções são importantes porque muitos elementos da realidade, como governo, dinheiro ou leis, são OR em sua ontologia, sendo criados pela consciência. Entretanto, a consciência que os cria é OI. Portanto, do fato de existirem objetos OR não se segue, então, que não seja possível obter um conhecimento epistemicamente objetivo acerca desse tipo de objeto. Tal discernimento seria relevante 
para a discursão de noções como computação, cognição, pensamento, inteligência, motivação, entre outras, pois essas apresentariam dois tipos diferentes de entendimento. Um senso que se refere a um fenômeno OI, psicologicamente real, e outro que diz respeito a um fenômeno que é relativo ao observador e dependente de uma consciência para existir.

Para contestar Bostrom, Searle procura estabelecer essa distinção de sentidos para a computação. Quando um ser humano computa mentalmente uma adição, como $2+2=4$, essa computação é algo real, intrínseca e OI. Entretanto, quando uma calculadora, ou computador pessoal realiza a mesma operação, a computação é relativa, dependente de uma interpretação humana ou OR. Nesse caso não há uma realidade psicológica, em um sentido OI, tudo o que acontece é um conjunto de transições de estado eletrônico que nós projetamos de uma maneira que possamos interpretar. Assim, os diversos fenômenos e estados físicos observer independent que ocorrem dentro de uma máquina digital somente são computações para uma consciência que possa interpretar esses processos. "Exceto para os casos de computações realizados por seres humanos conscientes, computação, tal como definido por Alan Turing e implementada em máquinas reais, é observer relative." (SEARLE, 2014, p. 3, tradução nossa).

A importância dessa percepção reside no fato de que podemos ampliar esse entendimento para as noções de inteligência, percepção, motivação, crença, racionalidade, dentre outras. Todas têm dois sentidos diferentes, um sentido onde identificamos fenômenos psicologicamente reais do tipo que acontece em seres humanos conscientes e outro do tipo onde distinguimos fenômenos relativos ao observador. Assim, no sentido intrínseco em que humanos têm inteligência, uma máquina não tem inteligência alguma. Não é questão de ter mais ou menos, não é uma comparação que pode ser feita. A noção de inteligência está nos olhos de quem observa. Aquilo que interpretamos como um ato inteligente de um computador é OR. Não importa quão rápido uma máquina digital processa informações, e este é o ponto chave, essa inteligência é relativa ao observador. O único sentido em que o computador tem inteligência não está em um sentido intrínseco de um fenômeno mental, mas unicamente em um sentido relativo ao observador.

Para a maioria dos propósitos, não importa se a inteligência de um computador é um fenômeno psicológico real ou não, argumentará Searle (2014). Porém, importa quando estamos preocupados com a perspectiva de criarmos uma raça de superinteligências mecânicas que podem se levantar e nos ameaçar. O problema, justificará Searle, é que computadores são totalmente não conscientes. Como demonstrado pelo argumento do quarto chinês, a computação em uma máquina digital, em um sentido observer independent, é apenas manipulação de símbolos, e como tal nunca conseguirá gerar semântica, intencionalidade ${ }^{2}$ ou consciência. A natureza dessa inferência não está restrita a qualquer estado particular de IA ou capacidade técnica específica dos computadores. Mesmo Bostrom (2018, p. 471) procura nos sensibilizar alertando que avanços técnicos em aprendizado de máquina, máquinas neurais de Turing, aprendizagem por reforço ou otimização bayesiana de hiperparâmetros, cada vez mais, nos levam para um ponto sem volta para o emergir de uma superinteligência. Entretanto, de fato, a natureza da refutação de Searle é totalmente independente de qualquer fronteira da tecnologia. Concerne unicamente à definição de computador digital, com aquilo que uma máquina digital é.

Uma tentativa de defender a validade das crenças de Bostrom frente à crítica de Searle é feita por Selmer Bringsjord, em seu artigo A Refutation of Searle on Bostrom (re: Malicious Machines) and Floridi (re: Information). No referido escrito, Bringsjord procura analisar especificamente a questão da necessidade ou não de

\footnotetext{
2 A característica pela qual os nossos estados mentais se dirigem a, ou são acerca de, ou se referem a, ou são de objetos e estados de coisas no mundo diferentes deles mesmos. (SEARLE, 1984, p. 21).
} 
consciência para uma máquina ser considerada maliciosa. Assim, ao examinar a ponderação de Searle, Bringsjord (2015, tradução nossa) estrutura o argumento do filósofo nos seguintes termos:

S1) Máquinas de computação apenas manipulam símbolos e, portanto, não podem ser conscientes.

S2) Uma máquina de computação maliciosa seria por definição uma máquina consciente.

S3) Portanto, nenhuma máquina de computação maliciosa pode existir, muito menos surgir no planeta Terra. Q.E.D.

Bringsjord aceita a verdade da primeira premissa S1, justificando tratar-se de uma proposição conjuntiva formada por uma primeira conjunta que é um fato lógico-matemático e uma segunda conjunta que é derivada do próprio argumento do quarto chinês de Searle (Bringsjord aceita a conclusão desse argumento). Porém, ele está convencido de que S2 é demonstravelmente falsa. Bringsjord acredita que se puder sustentar a verdade de uma proposição D', onde uma máquina de computação maliciosa não é necessariamente consciente, tal que D’ é ao mesmo tempo coerente e sensata, e afirmada por várias pessoas perfeitamente racionais, o argumento de Searle poderá ser rejeitado. Para fundamentar sua refutação ele propõe a seguinte ilustração:

O ano é 2025. Um robô policial inteligente e autônomo $\mathrm{R}$ acaba de atirar e matar uma norueguesa inocente. Antes de matar a mulher, o robô proclamou: "Eu desprezo os humanos de ascendência viking!" $\mathrm{R}$ então levantou seu braço letal, disparador de balas, e atirou repetidamente na mulher. $\mathrm{R}$ então disse: "Menos uma norueguesa nojenta capaz de andar pelas minhas ruas!" Uma investigação revela que, por razões que ainda não estão completamente entendidas, todos os símbolos internos relevantes na base de conhecimento e no sistema de planejamento de $\mathrm{R}$ correspondem perfeitamente com as estruturas observer independent de profunda malícia, conforme definido na literatura mais relevante de lógica de IA. Por exemplo, na lógica de dinâmica computacional intencional L guiando $\mathrm{R}$, foram encontradas as seguintes especificidades: Existe uma fórmula que expressa que $\mathrm{R}$ deseja (até o nível máximo de intensidade k) matar a mulher, com parâmetros temporais que se ajustam ao que aconteceu. Existe uma fórmula que expressa que $\mathrm{R}$ intenciona matar a mulher, com parâmetros temporais que se encaixam no que aconteceu. Existe uma fórmula que expressa que R conhece um plano de como matar a mulher com sua arma de fogo embutida, com parâmetros temporais adequados. O mesmo ocorre com relação ao conhecimento de R sobre a ancestralidade da vítima. E assim por diante. Em suma, a coleta e organização dessas fórmulas juntas constituem satisfatoriamente uma definição lógica D' de malícia, que diz que um robô é malicioso se, por uma questão de lógica e dados internos, pesquisáveis, deseja prejudicar pessoas inocentes por razões que não têm nada a ver com prevenir danos, salvar outrem ou autodefesa, etc. Ironicamente, a formulação de D' foi guiada por definições de malícia encontradas por renomados engenheiros lógicos de IA na literatura filosófica. (BRINGSJORD, 2015, p. 7, grifo nosso, tradução nossa).

Bringsjord acredita que com isso demonstrou que a argumentação de Searle é um conjunto formalmente contraditório ao acrescentar uma proposição necessariamente verdadeira D’ que é evidentemente a negação de S2. Para sustentar suas afirmações ele justifica que tal robô não é meramente uma especulação futurista, mas uma realidade factual já desenvolvida em seu próprio laboratório (BRINGSJORD; DAN; MEI, 2014), onde pesquisadores procuram construir máquinas computacionais que trabalham conforme a estrutura lógica descrita para R. Tais mentes digitais, assegura Bringsjord, possuem o que é descrito como consciência de acesso (BLOCK, 2015), que se limita àquilo que é relatável pelo sujeito e utilizada no raciocínio e na orientação racional da fala e da ação, sendo distinta da consciência fenomênica, a qual ultrapassa, em riqueza de detalhes, aquilo que é meramente declarável pelo indivíduo, e engloba tudo mais que é vivenciado ou experimentado pela mente. Portanto, segundo Bringsjord, a aceitabilidade racional do modelo de Bostrom estaria assegurada e Searle, por outro lado, equivocado quanto à necessidade da presença de consciência para que uma máquina possa ser considerada maliciosa. 
Entretanto, Bringsjord parece não compreender justamente a natureza ontológica das estruturas sintáticas internas presentes em R. Os símbolos internos nos sistemas de R, em um sentido observer independent, são meramente conjuntos de átomos e elétrons estruturados. A noção de malícia que Bringsjord alega existir ali só existe em um sentido observer relative, quando perscrutado por uma mente consciente. $\mathrm{R}$ não sabe o que é desprezo, ele chegou a essa resposta através da aplicação de uma série de regras formais. Não importa, nesse caso, quantas pessoas podem afirmar uma definição coerente de malícia ao observarem os símbolos da lógica interna de R. Essa noção de maldade, ou mesmo, o "desejo de prejudicar pessoas", só existe em um sentido para quem observa e pode dar um significado a esse conjunto de códigos.

Mesmo aquilo que é alegado como consciência de acesso não é consciência em um sentido OI, intrínseco. Igualmente aqui, a interpretação de que determinadas estruturas sintáticas correspondem a uma noção de consciência só existe em um sentido relativo ao observador. Tudo o que uma mente digital possui, em um sentido ontológico objetivo, são diferentes estados de natureza física e elétrica, ao contrário de uma consciência humana que apresenta uma realidade psicológica, ontologicamente objetiva e OI. Falar em desejos, desprezo, intenções ou malícia em mentes computacionais simplesmente não faz sentido, pois o que existe ali, a priori, são somente processos estruturados e comportamentos emulados para parecer a nós como se fossem fenômenos psicológicos.

Assim, por mais que o comportamento e estrutura lógica interna de uma máquina digital seja semelhante com a de um ser humano, reproduzindo com perfeição condutas julgadas maliciosas, não há razão em atribuir maldade a esse comportamento. Mas qual a diferença, nesse caso, quando atribuímos maldade a um ser humano? Por que atribuímos estados mentais a outros indivíduos e não a máquinas com comportamento semelhante? A questão primordial aqui não é porque atribuímos estados mentais a outros humanos e sim a natureza daquilo que estamos atribuindo. O que atribuímos a outras mentes humanas são estados mentais, porque nós, como indivíduos conscientes, temos estados mentais, e assim inferimos que esses mesmos estados estão presentes em outras pessoas porque elas possuem um sistema biológico semelhante ao nosso, e não simplesmente pelo comportamento que verificamos nelas. E isso é algo que não podemos estender aos computadores justamente pela natureza de sua condição: eles são apenas máquinas sintáticas, e como tais, falham em produzir sozinhos consciência, intencionalidade e significado, pois as propriedades internas de seu "mecanismo são definidas puramente de maneira formal ou sintática, e a sintaxe dessas operações não é, por si só, suficiente para garantir a presença de semântica ou de significado.” (SEARLE, 2007, p.3).

Portanto, Bostrom não nos oferece nenhuma justificativa plausível para crer que seu modelo de superinteligência supere o argumento do quarto chinês. Seu modelo de uma mente digital maliciosa, que intencional e deliberadamente, baseada em seus desejos e motivações, possa levantar-se contra a humanidade é irreal, simplesmente porque máquinas não têm desejos e motivações reais. Bostrom aposta toda sua especulação temerária no crescimento exponencial da tecnologia, porém a fronteira da passagem do sintático ao semântico é intransponível por máquinas computacionais como demonstrado pelo argumento do quarto chinês. Mesmo a variação argumentativa, proposta por Bringsjord, apresenta-se infrutífera por não distinguir a natureza ontológica de um fenômeno mental que só é possível a uma mente consciente. Pelo contrário, seu modelo, assim como o de Bostrom, está limitado ao caráter determinístico das regras e estruturas sintáticas idealizadas por uma mente consciente humana. 


\section{Conclusão}

Partindo da conjectura de um evento hipotético no qual uma IA se aperfeiçoaria rapidamente até alcançar um nível de inteligência sobre-humano, mediante o avanço tecnológico florescido na era atual da humanidade, Nick Bostrom procura gerar a consciência sobre os riscos de uma explosão de inteligência artificial e despertar preocupações reais a respeito daquilo que pode constituir um risco para o gênero humano: uma superinteligência de máquina avançada com suas próprias motivações e preferências.

No entanto, desde 1980 o argumento do quarto chinês tem motivado discussões efusivas acerca dos limites que podem ser alcançados por modelos computacionais no que tange às noções de replicação dos fenômenos mentais. Dessa maneira, a seguinte questão foi levantada: o argumento do quarto chinês é superado pela superinteligência de Bostrom?

Após caracterizar o argumento estruturado no experimento de pensamento do quarto chinês e o modelo de superinteligência de Bostrom foi possível sustentar que nenhuma das premissas do argumento proposto por Searle é demonstravelmente falsa pelo modelo de superinteligência de Bostrom. Corrobora isso o fato de que em seu modelo de super IA não há nada que indique que a estrutura computacional de uma superinteligência possa produzir fenômenos mentais que justifiquem as noções de intencionalidade, motivação, inteligência ou autonomia. Mesmo estendendo-se a análise com os argumentos de Bringsjord, a barreira sintática da mera manipulação de símbolos não é superada.

Computadores apenas manipulam símbolos não interpretados. Sugerir que mentes digitais, providas de intencionalidade, um dia poderão ser uma ameaça por agir de acordo com seus próprios interesses não é uma avaliação realista daquilo que podemos presumir dos avanços na inteligência artificial e computação. Não importa o quanto a tecnologia evolua ou a IA supere o desempenho humano em termos de simular o seu comportamento de fenômenos mentais, num jogo perfeito de imitar. Defensores da IA forte, como Bostrom e Bringsjord, acreditam que seja só uma questão de tempo e desenvolvimento tecnológico para que o computador supere o homem nesse jogo. A ironia dessa expectativa está no fato de que máquinas não podem nem sequer jogá-lo, pelo menos, não no mesmo sentido que nós.

\section{Referências}

BLOCK, Ned. (1995). On a confusion about a function of consciousness. Behavioral and brain sciences, v. 18, n. 2, p. 227-247.

BOSTROM, Nick. (2014). Superinteligência: Caminhos, perigos, estratégias. Rio De Janeiro: DarkSide Books, 2018.

BRINGSJORD, Selmer. (2015). A Refutation of Searle on Bostrom (re: Malicious Machines) and Floridi (re: Information). APA Newsletter on Philosophy and Computation, v. 15, n. 1, p. 7-9.

BRINGSJORD, Selmer; DAN, Thero; MEI, Si. (2014). Akratic robots and the computational logic thereof. 2014 IEEE International Symposium on Ethics in Science, Technology and Engineering. IEEE.

KURZWEIL, Ray. (2005). The singularity is near: When humans transcend biology. Penguin. . (1999). A Era das Máquinas Espirituais. Tradução de Fábio Fernandes. São Paulo: Aleph,

2007.

SEARLE, John R. (1980). Minds, brains, and programs. Behavioral and brain sciences, v. 3, n. 3, 
p. 417-424.

. (1984). Mente, Cérebro e Ciência. Trad. Artur Morão. Lisboa: Edições 70, 2000. 31, jan. (1990). Is the brain's mind a computer program?. Scientific American, v. 262, n. 1, p. 25-

. (2007). Filosofia da Linguagem: uma entrevista com John Searle. Tradução de Gabriel de Ávila Otheroff. ReVEL, v. 5, n. 8.

. (2014). What your computer can't know. The New York review of books, v. 9.

SEARLE, John R.; DENNETT, Daniel Clement; CHALMERS, David John. (1997). The mystery of consciousness. New York: New York Review of Books.

TURING, Alan M. (1950). Computing Machinery and Intelligence. Mind.

VINGE, Vernor. (1993). Technological singularity. VISION-21 Symposium sponsored by NASA Lewis Research Center and the Ohio Aerospace Institute, p. 30-31.

Artigo recebido em: 26 de agosto de 2020

Artigo aceito em: 12 de outubro de 2020 